\title{
HUBUNGAN KONDISI RUANGAN DAN PERSONAL HYGIENE TERHADAP KEJADIAN PENYAKIT KULIT PADA ASRAMA PUTRI PONDOK PESANTREN SULTAN HASANUDDIN KAB. GOWA Hidayat ${ }^{1}$ dan Ramlah ${ }^{2}$ \\ 1.2 Poltekkes Kemenkes Makassar \\ ramlah370@gmail.com
}

\begin{abstract}
Skin disease is one disease that still becomes public health problems in Indonesia and one of them often occurs in Pondok Pesantren because it is a vulnerable place inside the spread of skin diseases. The purpose of this research is to determine the correlation condition of the room and personal hygiene with the genesis of skin diseases Dormitory of Princess Pesantren Sultan Hasanuddin Kab. Gowa Year 2018. The research design using a cross-sectional design with a sample size of 205 people and 10 rooms room. The population was all santriwati Madrasah Tsanawiyah who live in Dormitory Princess Pondok Pesantren Sultan Hasanuddin. Primary data obtained by doing questionnaires, observing, and doing a measurement of the condition of Pondok Pesantren room. The results of research researched as much as 2 variables that are not eligible and 1 variable that meets health requirements within terms of room condition and 1 related variable and 1 variable not correlation to the incidence of skin diseases in personal terms hygiene, the result of the measurement of residential density variables are 7 rooms (70\%) not qualified health, habitual habit of changing clothes statistical test result using chi-square test obtained value $P=0.05 \& \mathrm{It} ; \alpha=0.05$ which means that there is a meaningful relationship between habit of changing clothes with the incidence of skin diseases. The conclusion is that the condition of the room is not eligible for health has a significant correlation to the incidence of skin diseases and personal hygiene habit of replacing clothing also has a significant correlation to events skin disease at the Boarding House Dormitory of Sultan Hasanuddin School Kab. Gowa.
\end{abstract}

Keywords: Condition of Room, Personal Hygiene, Skin Disease.

\section{ABSTRAK}

Penyakit kulit merupakan salah satu penyakit yang masih menjadi masalah kesehatan masyarakat di Indonesia dan satu diantaranya sering terjadi di Pondok Pesantren karena merupakan tempat yang rentan dalam penyebaran penyakit kulit. Tujuan penelitian ini adalah untuk mengetahui hubungan kondisi ruangan dan personal hygiene dengan kejadian penyakit kulit pada Asrama Putri Pondok Pesantren Sultan Hasanuddin Kab. Gowa Tahun 2018. Rancangan penelitian menggunakan desain cross sectional dengan jumlah sampel 205 orang dan 10 ruang kamar. Populasi penelitian adalah semua santriwati Madrasah Tsanawiyah yang tinggal di Asrama Putri Pondok Pesantren Sultan Hasanuddin. Data primer didapatkan dengan melakukan pengisian kuesioner, mengobservasi, serta melakukan pengukuran terhadap kondisi ruangan Pondok Pesantren. Hasil penelitian yang diteliti sebanyak 2 variabel yang tidak memenuhi syarat yaitu kepadatan hunian \& ventilasi dan 1 variabel yang memenuhi syarat kesehatan yaitu angka kuman di udara dalam hal kondisi ruangan dan 1 variabel yang berhubungan serta 1 variabel yang tidak berhubungan dengan kejadian penyakit kulit dalam hal personal hygiene, hasil pengukuran variabel kepadatan hunian yaitu 7 kamar (70\%), ventilasi yaitu 10 kamar $(100 \%)$ tidak memenuhi syarat kesehatan, variabel kebiasaan mengganti pakaian hasil uji statistik dengan menggunakan uji chi square diperoleh nilai $P=0,05 \leq \alpha=0,05$ yang berarti bahwa ada hubungan yang bermakna antara kebiasaan mengganti pakaian dengan kejadian penyakit kulit. Kesimpulan yang didapatkan yaitu kondisi ruangan yang tidak memenuhi syarat kesehatan memiliki hubungan yang signifikan terhadap kejadian penyakit kulit dan personal hygiene kebiasaan mengganti pakaian juga memiliki hubungan yang signifikan terhadap kejadian penyakit kulit pada Asrama Putri Pondok Pesantren Sultan Hasanuddin Kab. Gowa.

Kata Kunci : Kondisi Ruangan, Personal Hygiene, Penyakit Kulit.

\section{PENDAHULUAN}

Derajat kesehatan dipengaruhi oleh beberapa factor, yaitu factor lingkungan, perilaku, pelayanan kesehatan dan factor keturunan (H.L Blum). Dari keempat factor ini yang paling mempengaruhi tinggi rendahnya derajat kesehatan adalah factor lingkungan dan perilaku. Salah satu factor yang dapat mengubah perilaku serta sumber daya manusia menjadi produktif secara social dan ekonomis adalah pendidikan.

Penyakit kulit merupakan salah satu penyakit yang berhubungan dengan lingkungan dan perilaku manusia. Faktor lingkungan yang erat kaitannya dengan penyakit kulit antara lain penyediaan air bersih yang digunakan sebagai sumber air mandi dan cuci dari segi kualitas dan kuantitas. Air bersih yang digunakan harus mencukupi kebutuhan seharihari. Penyakit kulit yang timbul akibat kurangnya penyediaan air (water washed disease) adalah scabies, ulkus pada kulit dan yaws (frambusia/patek). (Susanna Dewi dkk, 2014).

Dari hasil observasi dan wawancara di Pondok Pesantren Sultan Hasanuddin yaitu asrama dalam keadaan overcrowded (jumlah penghuni kamar melebihi kapasitas), sehingga menimbulkan suasana gaduh (bising), serta penularan penyakit melalui udara mudah terjadi. Terdapatnya timbunan sampah disekitar sumur dan kurangnya wadah (container) untuk pembuangan sampah serta tempat sampah yang terbuka mengakibatkan sampah berserakan yang dapat menjadi tempat berkembangbiaknya vector seperti lalat, kecoa, dan 
Jurnal Sulolipu : Media Komunikasi Sivitas Akademika dan Masyarakat

Vol. 18 No 22018

e-issn : 2622-6960, p-issn : 0854-624X

tikus. Selain itu, di dalam kamar santriwati terdapat banyak pakaian yang di gantung sehingga bisa menyebabkan tempat bersarangnya nyamuk dan mikroorganisme lainnya. Adapun hasil wawancara yang dilakukan pada santriwati di pesantren tersebut yaitu adanya keluhan - keluhan pada penghuni asrama seperti keadaan yang pengap sehingga suasana sering kali gaduh atau bising serta beberapa santriwati yang mengeluh gatal gatal yang cukup menyiksa terutama pada malam hari.

Berdasarkan uraian latar belakang di atas maka penulis tertarik untuk melakukan penelitian yaitu : "Hubungan Kondisi Ruangan dan Personal Hygiene terhadap Kejadian Penyakit Kulit pada Asrama Putri Pondok Pesantren Sultan Hasanuddin Kab. Gowa".

\section{BAHAN DAN METODE}

\section{Lokasi Penelitian:}

Adapun lokasi untuk mengadakan penelitian di lingkungan Asrama Putri Pondok Pesantren Sultan Hasanuddin Kab. Gowa, dengan pertimbangan : a) Pondok Pesantren yang berada di wilayah kab. Gowa tersebut belum pernah dijadikan obyek penelitian. b) Pondok Pesantren Sultan Hasanuddin Kab. Gowa merupakan pusat pendidikan yang banyak diminati masyarakat khususnya masyarakat Kab. Gowa.

\section{Desain dan Variabel Penelitian}

Pondok Pesantren, selain dikenal sebagai wahana tempat belajar santri dan santriwati dalam mendalami ilmu agama Islam, namun Pondok Pesantren selama ini juga dikenal bermasalah dari aspek sanitasi. Berbagai penyakit berbasis lingkungan yang umum sering menjadi masalah di Pondok pesantren seperti penyakit kulit (kudis dan scabies) yang disebabkan oleh lingkungan yang kurang sehat di Pondok Pesantren. Bahkan ada gurauan dikalangan santri dan kyai bahwa belum sah jika seorang santri yang mondok disebuah pondok pesantren jika belum terserang penyakit kudis (scabies).

Adapun variabel penelitian pada penelitian ini terdiri dari 3 variabel. Yaitu variabel bebas yang terdiri dari kondisi ruangan dan personal hygiene, variabel terikat yaitu kejadian penyakit kulit pada santriwati pondok pesantren, serta variabel pengganggu yang terdiri dari suhu, kelembaban, dan pencahayaan.

\section{Populasi dan Sampel}

Populasi dalam penelitian ini adalah semua ruang kamar tidur di Asrama Putri Pondok Pesantren Sultan Hasanuddin Kab. Gowa sebanyak 10 kamar dan santriwati yang tinggal di Asrama tersebut sebanyak 205 orang dengan jenjang pendidikan Madrasah Tsanawiyah antara usia 12 15 Tahun.

Sampel dalam penelitian ini ditentukan secara total sampling yang dijadikan sebagai subjek penelitian.

\section{Pengumpulan data}

Sumber data terdiri dari 2 yaitu data primer diperoleh dari hasil observasi langsung dan wawancara menggunakan lembar kuesioner serta hasil pemeriksaan angka kuman di udara dari laboratorium mikrobiologi dan data sekunder diperoleh melalui penelusuran kepustakaan berupa referensi hasil penelitian sebelumnya, jurnal, artikel, maupun laporan pemerintah.

5. Analisa Data (Jika memakai program statistic, tuliskan uji utama apa yang digunakan)

Analisa data dilakukan dengan menggunakan tabel beserta pembahasannya dan disimpulkan dengan menggunakan menggunakan uji Chi Square dengan SPSS 25, Microsoft excel, dan Microsoft word.

HASIL

1. Kepadatan Hunian

Tabel 1

Distribusi Kepadatan Hunian pada Asrama Putri Pondok Pesantren Sultan Hasanuddin Tahun 2018

\begin{tabular}{|c|c|c|c|}
\hline $\begin{array}{l}\mathbf{N} \\
\mathbf{0} .\end{array}$ & Hasil Pengukuran & $\begin{array}{l}\text { Memenuhi } \\
\text { Syarat }\end{array}$ & $\begin{array}{c}\text { Tidak } \\
\text { Memenuh } \\
\text { i Syarat }\end{array}$ \\
\hline 1 & $15 \times 10 \mathrm{~m}^{2} / 37$ orang & $\sqrt{ }$ & \\
\hline 2 & $15 \times 10 \mathrm{~m}^{2} / 34$ orang & $\sqrt{ }$ & \\
\hline 3 & $16 \times 10 \mathrm{~m}^{2} / 28$ orang & $\sqrt{ }$ & \\
\hline 4 & $11 \times 5 \mathrm{~m}^{2} / 29$ orang & & $\sqrt{ }$ \\
\hline 5 & $5 \times 3 \mathrm{~m}^{2} / 6$ orang & & $\sqrt{ }$ \\
\hline 6 & $10 \times 4 \mathrm{~m}^{2} / 15$ orang & & $\sqrt{ }$ \\
\hline 7 & $10 \times 4 \mathrm{~m}^{2} / 15$ orang & & $\sqrt{ }$ \\
\hline 8 & $10 \times 4 \mathrm{~m}^{2} / 15$ orang & & $\sqrt{ }$ \\
\hline 9 & $10 \times 4 \mathrm{~m}^{2} / 15$ orang & & $\sqrt{ }$ \\
\hline 10 & $8 \times 4 \mathrm{~m}^{2} / 11$ orang & & $\sqrt{ }$ \\
\hline & Total & 3 & 7 \\
\hline & Persentase (\%) & 30 & 70 \\
\hline
\end{tabular}

Sumber: Data Primer 
Jurnal Sulolipu : Media Komunikasi Sivitas Akademika dan Masyarakat

Vol. 18 No 22018

e-issn : 2622-6960, p-issn : 0854-624X

\section{Angka Kuman di Udara}

Tabel 2

Distribusi Angka Kuman di Udara pada Asrama Putri Pondok Pesantren Sultan Hasanuddin Tahun 2018

\begin{tabular}{ccc}
\hline No. & Hasil $\left(\mathbf{C F U} / \mathbf{m}^{3}\right)$ & Keterangan \\
\hline 1 & 43 & Memenuhi syarat \\
2 & 32 & Memenuhi syarat \\
3 & 124 & Memenuhi syarat \\
4 & 106 & Memenuhi syarat \\
5 & 48 & Memenuhi syarat \\
6 & 34 & Memenuhi syarat \\
7 & 56 & Memenuhi syarat \\
8 & 28 & Memenuhi syarat \\
9 & 44 & Memenuhi syarat \\
10 & 56 & $\mathbf{1 0}$ \\
\hline \multicolumn{3}{c}{ Persentase (\%) }
\end{tabular}

Sumber: Data Primer

\section{Ventilasi}

Tabel 3

Distribusi Ventilasi pada Asrama Putri Pondok Pesantren

Sultan Hasanuddin Tahun 2018

\begin{tabular}{ccc}
\hline No. & $\begin{array}{c}\text { Hasil Pengukuran } \\
\left(\mathbf{m}^{\mathbf{2}}\right)\end{array}$ & Keterangan \\
\hline 1 & 12 & Tidak memenuhi syarat \\
2 & 10 & Tidak memenuhi syarat \\
3 & 0 & Tidak memenuhi syarat \\
4 & 2,25 & Tidak memenuhi syarat \\
5 & 0,75 & Tidak memenuhi syarat \\
6 & 3 & Tidak memenuhi syarat \\
7 & 3 & Tidak memenuhi syarat \\
8 & 3 & Tidak memenuhi syarat \\
9 & 3 & Tidak memenuhi syarat \\
10 & 1,5 & Tidak memenuhi syarat \\
\hline \multicolumn{3}{c}{ Total }
\end{tabular}

Sumber: Data Primer

\section{Kebiasaan Mandi}

Tabel 4

Distribusi Kebiasaan Mandi pada Asrama Putri Pondok Pesantren Sultan Hasanuddin Tahun 2018

\begin{tabular}{cccc}
\hline No. & $\begin{array}{c}\text { Kebiasaan } \\
\text { Mandi }\end{array}$ & Jumlah & Persentase \\
\hline 1 & $\begin{array}{c}\text { Tidak } \\
\text { Memenuhi } \\
\text { Syarat }\end{array}$ & 179 orang & $87 \%$ \\
2 & $\begin{array}{c}\text { Memenuhi } \\
\text { syarat }\end{array}$ & 26 orang & $13 \%$ \\
\hline & Total & 205 & $100 \%$
\end{tabular}

Sumber: Data Primer

Adapun hasil pengujian hubungan antara kebiasaan mandi dengan kejadian penyakit kulit pada santriwati, sebagai berikut:

Tabel 5.6

Hubungan Kebiasaan Mandi dengan Kejadian Penyakit Kulit pada Asrama Putri Pondok Pesantren Sultan Hasanuddin Kab. Gowa Tahun 2018

\begin{tabular}{|c|c|c|c|c|c|c|c|}
\hline \multirow{3}{*}{$\begin{array}{l}\text { Kebiasan } \\
\text { Mandi }\end{array}$} & \multicolumn{4}{|c|}{ Penyakit Kulit } & \multirow{3}{*}{$\begin{array}{l}\text { Jumla } \\
\text { h }\end{array}$} & \multirow{3}{*}{$\%$} & \multirow{3}{*}{$\begin{array}{l}\text { Statist } \\
\mathrm{k}\end{array}$} \\
\hline & \multicolumn{2}{|c|}{$\begin{array}{l}\text { Tidak } \\
\text { Menderita }\end{array}$} & \multicolumn{2}{|c|}{ Menderita } & & & \\
\hline & $\mathrm{n}$ & $\%$ & $n$ & $\%$ & & & \\
\hline \multirow{2}{*}{$\begin{array}{l}\text { Tidak } \\
\text { Memenu } \\
\text { hi Syarat }\end{array}$} & 72 & 78 & 2 & 21.8 & 92 & 10 & \multirow{4}{*}{$P=0,5$} \\
\hline & & 2 & 0 & & & 0 & \\
\hline \multirow{2}{*}{$\begin{array}{l}\text { Memenu } \\
\text { hi Syarat }\end{array}$} & 84 & 74 & 2 & 25,7 & 113 & 10 & \\
\hline & & 3 & 9 & & & 0 & \\
\hline \multirow[t]{2}{*}{ Jumlah } & 15 & 76 & 4 & 23,1 & 205 & 10 & \\
\hline & 6 & 0 & 9 & 0 & & 0 & \\
\hline
\end{tabular}

\section{Kebiasaan Mengganti Pakaian \\ Tabel 5}

Distribusi Kebiasaan Mengganti Pakaian pada Asrama Putri

Pondok Pesantren Sultan Hasanuddin Tahun 2018

\begin{tabular}{|c|c|c|c|}
\hline No. & $\begin{array}{c}\text { Kebiasaan } \\
\text { Mengganti } \\
\text { Pakaian }\end{array}$ & Jumlah & Persentase \\
\hline 1 & $\begin{array}{c}\text { Tidak Memenuhi } \\
\text { Syarat }\end{array}$ & 108 orang & $53 \%$ \\
\hline 2 & Memenuhi syarat & 97 orang & $47 \%$ \\
\hline & Total & 205 & $100 \%$ \\
\hline
\end{tabular}


Jurnal Sulolipu : Media Komunikasi Sivitas Akademika dan Masyarakat

Vol. 18 No 22018

e-issn : 2622-6960, p-issn : 0854-624X

Adapun hasil pengujian hubungan antara kebiasaan mengganti pakaian dengan kejadian penyakit kulit pada santriwati, sebagai berikut:

Tabel7

Hubungan Kebiasaan Mengganti Pakaian dengan Kejadian Penyakit Kulit pada Asrama Putri Pondok Pesantren Sultan Hasanuddin Kab. Gowa Tahun 2018

\begin{tabular}{|c|c|c|c|c|c|c|c|}
\hline \multirow{3}{*}{$\begin{array}{c}\text { Kebiasan } \\
\text { Menggant } \\
\text { i Pakaian }\end{array}$} & \multicolumn{4}{|c|}{ Penyakit Kulit } & \multirow{3}{*}{$\begin{array}{c}\text { Jumla } \\
\mathrm{h}\end{array}$} & \multirow{3}{*}{$\%$} & \multirow{3}{*}{$\begin{array}{c}\text { Statisti } \\
\text { k }\end{array}$} \\
\hline & \multicolumn{2}{|c|}{$\begin{array}{c}\text { Menderit } \\
\text { a }\end{array}$} & \multicolumn{2}{|c|}{$\begin{array}{c}\text { Tidak } \\
\text { Menderita }\end{array}$} & & & \\
\hline & $\mathrm{n}$ & $\%$ & $\mathrm{n}$ & $\%$ & & & \\
\hline \multirow{2}{*}{$\begin{array}{c}\text { Memenuh } \\
\text { i Syarat }\end{array}$} & 4 & 53 , & 37 & 46 & 79 & 10 & \multirow{4}{*}{$P=0,05$} \\
\hline & 2 & 2 & & 8 & & 0 & \\
\hline \multirow{2}{*}{$\begin{array}{c}\text { Tidak } \\
\text { Memenuh } \\
\text { i Syarat }\end{array}$} & 5 & 39 , & 75 & 60 & 126 & 10 & \\
\hline & 0 & 7 & & 3 & & 0 & \\
\hline \multirow{2}{*}{ Jumlah } & 9 & 44 , & 11 & 55 & 205 & 10 & \\
\hline & 2 & 9 & 3 & 1 & & 0 & \\
\hline
\end{tabular}

\section{PEMBAHASAN}

\section{Kepadatan Hunian}

Permasalahan yang berkaitan dengan kejadian penyakit kulit di Pondok Pesantren adalah gatal - gatal yang banyak diderita oleh santri, kasus ini terjadi pada daerah padat penghuni dan jumlah kasus yang banyak terjadi yaitu pada pesantren. Kepadatan dapat dilihat dari kepadatan hunian ruang tidur yaitu luas ruangan tidur minimal $4 \mathrm{~m}^{2}$ dan tidak dianjurkan lebih dari dua orang dalam satu ruangan tidur, kecuali anak dibawah usia 5 tahun berdasarkan Keputusan Menteri Kesehatan RI Nomor : 829/MENKES/VII/1999.

Hasil penelitian menunjukkan bahwa variabel kepadatan hunian ruang tidur memiliki hubungan dengan kejadian penyakit kulit di asrama putri Pondok Pesantren Sultan Hasanuddin Kab. Gowa. Hal ini sesuai dengan penelitian Ma'rufi (2005) yang menjelaskan bahwa santri yang tinggal di pemondokan dengan kepadatan hunian tinggi mempunyai prevalensi menderita penyakit kulit sebesar $71,40 \%$ dan menurut Audhah (2012) menjelaskan bahwa santri yang berada pada kepadatan hunian kamar padat berisiko menderita penyakit kulit sebanyak 48,7 kali dibandingkan dengan santri yang berada pada kepadatan hunian kamar tidak padat. Permasalahan yang berkaitan dengan kejadian penyakit kulit banyak di derita oleh santri yang tinggal asrama pada daerah padat penghuni.
Penyakit kulit terdeteksi apabila menjangkiti lebih dari 1 orang dalam satu ruangan tidur.

Berdasarkan pada pedoman penilaian pemeriksaan kepadatan hunian (Keputusan Menteri Kesehatan RI Nomor : 829/MENKES/VII/1999) maka dapat dilihat bahwa upaya kesehatan dari Asrama Putri Pondok Pesantren Sultan Hasanuddin Kab. Gowa ini belum cukup baik, dapat dilihat pada tabel 5.1 penghuni kamar pada asrama santriwati cukup overcrowded, dilihat dari hasil penelitian yaitu sebanyak $70 \%$ kamar yang tidak memenuhi syarat kesehatan dan dapat di lihat pada tabel 5.8 sebanyak 92 orang santriwati yang mengeluh gatal pada 6 bulan terakhir, yang berarti bahwa terdapat hubungan antara kepadatan hunian dengan kejadian penyakit kulit pada asrama putri Pondok Pesantren Sultan Hasanuddin Kab. Gowa tahun 2018.

Adapun hasil pengukuran pada 10 kamar di asrama tersebut ada 7 kamar yang overcrowded atau jumlah penghuni yang melebihi kapasitas, kamar 1 yang tidak memenuhi syarat luas lantainya yaitu $55 \mathrm{~m}^{2}$ sedangkan jumlah penghuninya sebanyak 29 orang, kamar 2 luas lantainya $15 \mathrm{~m}^{2}$ sedangkan jumlah penghuni sebanyak 6 orang, kamar 3 luas lantainya $32 \mathrm{~m}^{2}$ sedangkan jumlah penghuni sebanyak 11 orang, dan sebanyak 4 kamar luas lantainya $40 \mathrm{~m}^{2}$ sedangkan penghuni kamar masing - masing 15 orang.

Berdasarkan hasil pengamatan dan pengukuran langsung mengenai variabel kepadatan hunian dapat dikatakan bahwa lingkungan tempat tinggal santriwati responden tidak memenuhi syarat kesehatan hal ini didasari karena para santriwati berada dalam satu ruangan yang setiap tempat tidurnya hanya di batasi oleh lemari dan masing - masing hunian ruang kamar cukup padat sehingga menyebabkan kondisi kamar pengap dan lembab. Hal ini dapat menyebabkan bakteri penyabab penyakit kulit tumbuh subur dan berkembang biak.

\section{Angka Kuman di Udara}

Perhitungan angka kuman yang melebihi standar yang telah ditetapkan akan mengindikasi adanya pencemaran yang tinggi pada suatu ruangan, dan akan meningkatkan risiko terjadinya penularan penyakit pada suatu ruangan. Angka kuman udara harus memenuhi syarat kesehatan karena lingkungan tempat tinggal bisa menyebabkan penularan penyakit 
dengan mudah apabila ruangan tempat tinggal tidak memenuhi syarat kesehatan.

$$
\text { Setelah dilakukan pemeriksaan }
$$

didapatkan hasil pengambilan sampel udara dapat dilihat pada tabel 5.2 hasil pemeriksaan angka kuman di udara yaitu $100 \%$ memenuhi syarat. Berdasarkan pada pedoman penilaian pemeriksaan angka kuman di udara (Peraturan Menteri Kesehatan RI Nomor : 1077/MENKES/PER/V/2011) maka dapat dilihat bahwa upaya kesehatan dari Asrama Putri Pondok Pesantren Sultah Hasanuddin Kab. Gowa ini cukup baik dalam hal pemeriksaan angka kuman di udara.

Kelemahan pada saat pemeriksaan angka kuman di udara yaitu peneliti tidak menggunakan kontrol sebagai pembanding sehingga hasil pengukuran tidak akurat, jarak pengambilan sampel dan laboratorium tempat pemeriksaan cukup jauh sehingga dalam perjalanan sampel di simpan dalam wadah dan beri es kering (dry es), dalam perjalanan tersebut bakteri yang tergolong termofil dan hypertermofil bisa mati karena berada pada suhu rendah. Setelah berada di laboratorium sampel tersebut langsung di inkubasikan dengan suhu $35-37^{\circ} \mathrm{C}$, sampel yang berada dalam wadah dengan suhu rendah dan langsung di inkubasikan dengan suhu tinggi dapat menyebabkan kematian pada sebagian bakteri.

Meskipun semua ruang kamar memenuhi syarat dalam hal pemeriksaan angka kuman di udara namun tidak menutup kemungkinan bahwa kuman di udara dapat menularkan penyakit kulit pada santriwati, adapun faktor - faktor yang mempengaruhi berkembangbiaknya kuman di udara pada Asrama Putri Pondok Pesantren Sultan Hasanuddin Kab. Gowa yaitu kelembaban yang tidak memenuhi syarat, dapat dilihat pada tabel 5.4 kelembaban pada ruang kamar santriwati $100 \%$ tidak memenuhi syarat. Kelembaban dalam ruang juga dapat disebabkan kurangnya cahaya yang masuk secara langsung ke dalam ruangan, sehingga area ruangan yang tersinari oleh matahari terbatas dan tidak cukup untuk mengurangi kelembaban. Hal tersebut menunjukkan bahwa ada hubungan kelembaban dengan angka kuman di udara pada Asrama Putri Pondok Pesantren Sultan Hasanuddin Kab. Gowa.

Selain kelembaban, faktor yang dapat mempengaruhi berkembangnya angka kuman di udara yaitu pencahayaan, berdasarkan hasil penelitian yang dapat dilihat pada tabel 5.12 yaitu sebesar $60 \%$ kamar yang tidak memenuhi syarat yaitu $<60$ lux. Pencahayaan yang kurang merupakan kondisi yang disukai bakteri karena dapat tumbuh dengan baik pada kondisi gelap. Pencahayaan alami dari sinar matahari di samping menyebarkan sinar panas ke bumi, juga memancarkan sinar UV yang mematikan mikroba.

Adapun kuman di udara yang dapat menyebabkan penyakit kulit yaitu kuman Staphylococcus aureus, ciri - ciri seseorang yang terjangkit kuman tersebut dapat ditandai gatal, ruam merah, benjolan besar dan keras, berisi nanah, terasa nyeri, meradang, dan dapat juga disertai tidak enak badan, mudah lelah bahkan demam. Berdasarkan tabel 5.8 sebanyak 92 orang santriwati yang mengeluh gatal pada 6 bulan terakhir.

\section{Ventilasi}

Ventilasi ruang tidur yang diperoleh dalam penelitian ini didapatkan bahwa ada hubungan yang signifikan dengan kejadian penyakit kulit karena dari hasil pengukuran ventilasi ruang tidur yaitu $100 \%$ tidak memenuhi syarat berdasarkan pada pedoman penilaian pemeriksaan ventilasi (Keputusan Menteri Kesehatan RI Nomor : 829/MENKES/VII/1999).

Hal ini sesuai dengan penelitian Wirawan (2011) yang menyebutkan bahwa ventilasi sangat erat hubungannya dengan angka kesakitan penyakit menular terutama penyakit kulit karena ventilasi merupakan salah satu kondisi sanitasi yang apabila kondisi sanitasi tersebut tidak sehat akan menjadi penyebab dari rendahnya taraf kesehatan jasmani dan rohani serta memudahkan terjangkitnya penyakit serta mengurangi daya kerja atau daya produktif seseorang.

Berdasarkan observasi peneliti pada asrama putri Pondok Pesantren Sultan Hasanuddin Kab. Gowa tahun 2018, variabel ventilasi $100 \%$ tidak memenuhi syarat. Ventilasi tersebut tidak digunakan sebagaimana mestinya karena lubang penghawaan ditutup oleh plastik dan kain gorden secara permanen dan tidak bisa dibuka oleh para santri karena tidak terjangkau.

Ventilasi yang digunakan dalam ruangan harus memenuhi syarat kesehatan yaitu luas lubang ventilasi tetap (permanen) minimal 5\% dari luas lantai ruangan dan luas lubang ventilasi 
insidentil yaitu ventilasi yang dapat dibuka dan ditutup minimal 5\% dari luas lantai, sehingga luas ventilasi permanen dan insidentil adalah $10 \%$ dari luas lantai ruangan. Adapun ventilasi yang digunakan pada ruang tidur Aspuri Ponpes Sultan Hasanuddin yaitu ventilasi permanen, diukur dengan menggunakan alat bantu yaitu meter.

\section{Kebiasaan Mandi}

Personal hygiene yang dimaksud dalam penelitian ini adalah suatu tindakan responden/santri untuk menjaga dan memelihara kebersihan dan kesehatan diri mereka. Meliputi dari kebiasaan mandi, penggunaan sabun, kebersihan kuku, kebersihan pakaian, kebiasaan memakai handuk dan kebersihan di tempat tidur para santri.

Kejadian penyakit kulit lebih sering dilaporkan dari tempat yang padat, lingkungan social ekonomi rendah, kondisi yang tidak higienis dan orang dengan hygiene perorangan yang buruk juga terinfeksi.

Berdasarkan crosstabulation untuk mengetahui hubungan antara kebiasaan mandi dengan kejadian penyakit kulit di asrama putri Pondok Pesantren Sultan Hasanuddin Kab. Gowa mendapatkan hasil yaitu dari 92 responden yang memiliki kebiasaan mandi tidak memenuhi syarat dilihat 72 responden yang tidak berpenyakit kulit dan 20 responden yang berpenyakit kulit. Sedangkan, dari 113 responden yang memiliki kebiasaan mandi memenuhi syarat, diketahui bahwa 84 responden yang tidak berpenyakit kulit dan 49 responden yang berpenyakit kulit.

Berdasarkan tabel 5.6 hasil analisis bivariate dengan menggunakan uji chi square diperoleh nilai $\mathrm{P}=0,51<\alpha=0,05$ maka $\mathrm{Ha}$ di tolak dan nilai Ho diterima dengan kesimpulan bahwa tidak ada hubungan yang bermakna antara kebiasaan mandi dengan kejadian penyakit kulit. Hal ini tidak sejalan dengan penelitian Rianti (2010) yang mengatakan bahwa ada hubungan yang signifikan antara mandi pakai sabun dengan kejadian penyakit kulit di Kecamatan Asemworo Surabaya dan penelitian Audhah (2012) menjelaskan bahwa kontak dengan santri yang menderita penyakit kulit berisiko tertular penyakit kulit 48 kali dibandingkan mereka yang tidak pernah kontak dengan orang yang menderita penyakit kulit.
Serta Penelitian Ma'rufi (2005) yang menyatakan bahwa sebagian besar santri yang mempunyai personal hygiene yang jelek menderita penyakit kulit sebanyak $73,70 \%$ sedangkan jika dilihat dari sub variabel personal hygiene maka terdapat hubungan yang signifikan antara kejadian penyakit kulit yaitu frekuensi mandi pakai sabun dan penggunaan tempat tidur.

Dikatakan pula bahwa hygiene perorangan merupakan salah satu usaha yang dapat mencegah kejadian penyakit kulit, dikarenakan media transmisi kuman penyebab penyakit kulit untuk berpindah tempat dan menyebabkan penularan dapat secara langsung maupun tidak langsung.

Berdasarkan hasil observasi dan wawancara yang dilakukan di Pondok Pesantren Sultan Hasanuddin Kab. Gowa 2018 mendapatkan hasil bahwa ada 179 orang santriwati yang memiliki kebiasaan mandi yang kurang baik yaitu mandi hanya 1 kali sehari, menggunakan shampoo kurang dari 3 kali seminggu, jarang mencuci dan mengganti handuk seminggu sekali, alasan santriwati mandi hanya 1 kali sehari dikarenakan santriwati malas menunggu antrean untuk mandi ataupun malas mengangkat air masuk ke dalam kamar mandi, sehingga hal inilah yang dapat menimbulkan perkembangan dan sebagai sumber penularan penyakit kulit.

Adapun sumber air untuk mandi santriwati yaitu sumur gali, hasil pengamatan air sumur gali yaitu tidak berasa, tidak berbau, dan tidak berwarna, jika dilihat dari hasil pengamatan secara fisik sumber air untuk MCK telah memenuhi syarat kesehatan.

\section{Kebiasaan Mengganti Pakaian}

Personal hygiene yang dimaksud dalam penelitian ini adalah suatu tindakan responden/santri untuk menjaga dan memelihara kebersihan dan kesehatan diri mereka. Meliputi dari kebiasaan mandi, penggunaan sabun, kebersihan kuku, kebersihan pakaian, kebiasaan memakai handuk dan kebersihan di tempat tidur para santri.

Kejadian penyakit kulit lebih sering dilaporkan dari tempat yang padat, lingkungan social ekonomi rendah, kondisi yang tidak higienis dan orang dengan hygiene perorangan yang buruk juga terinfeksi. 


\begin{tabular}{|c|c|}
\hline $\begin{array}{l}\text { Berdasarkan crosstabulation untuk } \\
\text { mengetahui hubungan antara kebiasaan } \\
\text { mengganti pakaian dengan kejadian penyakit } \\
\text { kulit di asrama putri Pondok Pesantren Sultan } \\
\text { Hasanuddin Kab. Gowa mendapatkan hasil yaitu } \\
\text { dari } 79 \text { responden yang yang memiliki kebiasaan } \\
\text { mengganti pakaian memenuhi syarat dilihat } 42 \\
\text { responden yang berpenyakit kulit dan } 37 \\
\text { responden yang tidak berpenyakit kulit. } \\
\text { Sedangkan dari } 126 \text { responden yang memiliki } \\
\text { kebiasaan mengganti pakaian tidak memenuhi } \\
\text { syarat, diketahui bahwa } 50 \text { responden yang } \\
\text { berpenyakit kulit dan } 75 \text { responden yang tidak }\end{array}$ & $\begin{array}{l}\begin{array}{l}\text { yang dapat dilakukan adalah melakukan } \\
\text { pemberdayaan, promosi } \\
\text { penyelenggaraan } \\
\text { pemeriksaan kualitas air. } \\
\text { Melakukan kebiasaan seperti kebiasaan }\end{array} \\
\text { mengganti pakaian, tidak memakai pakaian yang } \\
\text { lembab, memakai pakaian dalam keadaan } \\
\text { bersih, tidak saling meminjam handuk dengan } \\
\text { temannya serta bertukar pakaian, dan kebiasaan } \\
\text { menggunting kuku, dapat mengurangi risiko } \\
\text { terkena penyakit kulit dan para santri juga tidak } \\
\text { akan memeriksakan penyakitnya sebelum benar } \\
\text { - benar parah. }\end{array}$ \\
\hline
\end{tabular}
berpenyakit kulit.

Dengan hasil uji statistik dengan menggunakan uji chi square diperoleh nilai $\mathrm{P}=$ $0,05<\alpha=0,05$ maka $\mathrm{Ho}$ di tolak dan nilai $\mathrm{Ha}$ diterima dengan kesimpulan bahwa ada hubungan yang bermakna antara Kebiasaan mengganti pakaian dengan kejadian penyakit kulit.

Penelitian ini sejalan dengan penelitian sebelumnya pada tahun 2011. Analisis bivariate hubungan antara hygiene perseorangan dengan kejadian penyakit kulit didapat nilai $\rho$ sebesar $0,001 \quad(\rho<0,05)$ maka secara statistic terdapat hubungan yang signifikan antara hygiene perorangan dengan kejadian penyakit kulit.

Berdasarkan hasil observasi dan wawancara yang dilakukan di Pondok Pesantren Sultan Hasanuddin Kab. Gowa 2018 mendapatkan hasil bahwa ada beberapa santriwati yang menggunakan pakaian berulang, menggunakan pakaian dalam keadaan tidak bersih dan seringkali lembab serta saling meminjam handuk kepada temannya sehingga hal inilah yang dapat menimbulkan perkembangan dan sebagai sumber penularan penyakit kulit.

Kesehatan pribadi merupakan hal yang sangat penting bagi seseorang dan untuk memiliki kondisi sehat, hanya pribadi masing masing yang mampu mengkondisikannya.B. Kondisi sehat bisa diperoleh apabila setiap pribadi berperilaku atau memiliki perilaku hidup bersih dan sehat. Sebagai contoh, apabila seseorang tidak bersih dalam merawat tubuhnya, maka kesehatannya akan terganggu dan akan mengakibatkan terserang penyakit. Peran serta dari pengelola pesantren maupun institusi terkait (puskesmas) juga sangat dibutuhkan untuk menumbuhkan perilaku personal hygiene yang baik bagi para santri, hal

\section{A. KESIMPULAN}

Berdasarkan penelitian yang telah dilakukan maka dapat ditarik beberapa kesimpulan sebagai berikut :

1. Variabel kepadatan hunian yaitu sebanyak 7 kamar $(70 \%)$ yang tidak memenuhi syarat kesehatan pada asrama putri Pondok Pesantren Sultan Hasanuddin Kab. Gowa.

2. Variabel angka kuman yaitu sebanyak 10 kamar (100\%) yang memenuhi syarat pada asrama putri Pondok Pesantren Sultan Hasanuddin Kab. Gowa.

3. Variabel ventilasi yaitu sebanyak 10 kamar $(100 \%)$ yang tidak memenuhi syarat variabel ventilasi pada asrama putri Pondok Pesantren Sultan Hasanuddin Kab. Gowa.

4. Variabel kebiasaan mandi dapat disimpulkan bahwa tidak terdapat hubungan antara kebiasaan mandi dengan kejadian penyakit kulit pada asrama putri Pondok Pesantren Sultan Hasanuddin Kab. Gowa.

5. Variabel kebiasaan mengganti pakaian dapat disimpulkan bahwa terdapat hubungan antara kebiasaan mengganti pakaian dengan kejadian penyakit kulit pada asrama putri Pondok Pesantren Sultan Hasanuddin Kab. Gowa.

\section{B. SARAN}

1. Bagi Santriwati

Santriwati Pondok Pesantren agar berperilaku hidup bersih dan sehat disegala bidang, membiasakan mandi pakai sabun 2 kali sehari serta tidak membiasakan untuk saling meminjam handuk kepada temannya. 
Jurnal Sulolipu : Media Komunikasi Sivitas Akademika dan Masyarakat

Vol. 18 No 22018

e-issn : 2622-6960, p-issn : 0854-624X

2. Bagi Pengelola Pondok Pesantren

Untuk pengelola pesantren sebaiknya merenovasi ruangan agar memenuhi syarat kesehatan, serta membuat kebijakan yang mengatur pengelolaan kesehatan lingkungan dan perilaku santri untuk selalu melakukan personal hygiene dan para ustadz, ustadzah pondok pesantren agar melakukan pengawasan dan turun langsung mengintervensi dalam proses perubahan perilaku personal hygiene

santriwati karena para santriwati cenderung lebih patuh pada peraturan Pondok Pesantren.

3. Bagi Institusi Terkait

Sebaiknya Puskesmas bekerja sama dengan Pesantren dalam mengoptimalkan Poskestren untuk meningkatkan pengoptimalan perilaku personal hygiene demi terciptanya kesehatan dan kesejahteraan warga pesantren. Serta memberikan pendidikan kesehatan kepada warga pesantren.

\section{DAFTAR PUSTAKA}

Achmadi, Umar Fahmi. 2011. Dasar Dasar Penyakit Berbasis Lingkungan. Jakarta: PT Rajagrafindo Persada

Audiah, N. 2012. Faktor Risiko Skabies pada Siswa Pondok Pesantren (kajian di Pondok Pesantren Darul Hijar Kelurahan Cindai Alus, Kecamatan Martapura, Kabupaten Banjar Provinsi Kalimantan Selatan). http://media.neliti.com. Skirpsi dipublikasikan di akses tanggal 09 Juli 2018

Depkes R.I. 2004. Pedoman Teknis Pengendalian Faktor Risiko Kesehatan Lingkungan di Sekolah. Jakarta: Dirjen P2M dan PLP Depkes R.I

Damopolii, Muljon. 2011. Pesantren modern IMMIM Percetakan muslim modern. Jakarta: Rajawali Pers

Fitriawati. 2014. Hubungan Factor Personal Hygiene, Sanitasi Lingkungan, dan Status Nutrisi dengan Kejadian Scabies pada Santriwati di Pondok Pesantren Nurul Ummah Kotagede Yogyakarta. Skripsi. Jurusan Keperawatan Stikes 'Aisyiyah. Yogyakarta. http://digilib.unisayogya.ac.id. Di akses tanggl 21 Januari 2018

Ma'Rufi, 2005. Faktor Sanitasi Lingkungan yang Berperan Terhadap Prevalensi Penyakit Skabies. Jurnal Kesehatan Lingkungan. Vol 2 No 1: Surabaya.

Notoatmodjo, Soekidjo. 2007. Promosi Kesehatan dan IImu Perilaku. Jakarta: Rieka Cipt

Republik Indonesia. 1999. Kepmenkes Nomor 829 Tentang Persyaratan Kesehatan Perumahan. Jakarta

Republik Indonesia. 2009. Nomor 36. Tentang Kesehatan.

Republik Indonesia. 2011. Permenkes Nomor 1077 Tentang Pedoman Penyehatan Udara dalam Ruang Rumah. Jakarta

Republik Indonesia. 2017. Profil kesehatan Indonesia tahun 2016. Jakarta.

Rianti, E. D. 2010. Analisis tentang Higiene dan Sanitasi Lingkungan dengan Penyebab terjadinya Penyakit Kulit di Kecamatan Asemrowo. Surabaya. Hal 1-10

Rosmila. 2013. Sanitasi dan Perilaku Personal Hygiene Santri Pondok Pesantren Darul Abrar Kabupaten Bone. Skripsi. Jurusan Kesehatan Masyarakat UIN Alauddin. Makassar. http://repository.uinalauddin.ac.id. Di akses tanggal 21 Januari 2018 
Jurnal Sulolipu : Media Komunikasi Sivitas Akademika dan Masyarakat

Vol. 18 No 22018

e-issn : 2622-6960, p-issn : 0854-624X

Sajida, A. D. 2012. Hubungan Personal Hygiene dan Sanitasi Lingkungan dengan Keluhan Penyakit Kulit di Kelurahan Denai Kecamatan Medan Denai Kota Medan. Medan : Universitas Sumatera Utara. http://jurnal.usu.ac.id. Diakses tanggal 21 januari 2018

Slamet, Juli Soemirat. 2009. Kesehatan Lingkungan. Yogyakarta: Gadjah Mada University Press

Wahyuni Sahani, Inayah. 2014. Panduan Praktikum Mikrobiologi. Makassar : Kementerian Kesehatan Republik Indonesia Politeknik Kesehatan Makassar Jurusan Kesehatan Lingkungan.

Wawan A, M Dewi. 2010. Teori \& Pengukuran Pengetahuan, Sikap, dan Perilaku Manusia. Yogyakarta: Nuha Medika

Widiastuti Ani, Susanna Dewi. 2014. Kondisi Lingkungan dan Personal Hygiene dengan Kejadian Penyakit Kulit di Asrama Pondok Pesantren "A" Kabupaten Bekasi. Skripsi. Jurusan Kesehatan Lingkungan Universitas Indonesia. Yogyakarta. http://lib.iu.ac.id. Di akses tanggal 21 Januari 2018

Wirawan, A., \& Ulfa Nurullita, R. A. 2011. Hubungan Hygiene Perorangan dengan Sanitasi Lapas terhadap Kejadian Penyakit Herpes di Lapas Wanita Kelas II A Semarang. Jurnal Kesehatan Lingkungan, Vol. 7 No.1. http://jurnal.lib.unair.ac.id. Di akses tanggal 21 Januari 2018 